\title{
Phylogenetic Relationships of the Filamentous Sulfur Bacterium Thiothrix ramosa Based on 16S rRNA Sequence Analysis $\dagger$
}

\author{
MARTIN F. POLZ, ${ }^{1}$ ELENA V. ODINTSOVA,${ }^{2} \ddagger$ AND COLLEEN M. CAVANAUGH ${ }^{1 *}$ \\ The Biological Laboratories, Harvard University, Cambridge, Massachusetts $02138,{ }^{1}$ and \\ Woods Hole Oceanographic Institution, Woods Hole, Massachusetts $02543^{2}$
}

\begin{abstract}
The phylogeny of Thiothrix ramosa based on 16S rRNA sequences was determined. This species is the first species in this genus that has been shown to be capable of autotrophic growth with reduced sulfur compounds as sole energy sources. $T$. ramosa forms a monophyletic clade with Thiothrix nivea, as determined by distance, parsimony, and maximum-likelihood methods. Both of these species clearly belong to the gamma subdivision of the Proteobacteria, where they are loosely associated with other sulfur-oxidizing chemoautotrophic organisms.
\end{abstract}

Bacteria belonging to the genus Thiothrix are characterized by their distinct morphological features $(12,13)$. These organisms form ensheathed filaments which accumulate sulfur internally in the presence of sulfide and have the ability to attach to substrates by means of holdfasts. The filaments often grow in a rosette-like array and can produce gliding gonidia from their unattached ends. The primary natural habitats of Thiothrix strains are sulfide-containing, flowing waters, in which the filaments can produce one of the most conspicuous microbial aggregations seen in nature (13). These organisms also occur regularly in activated sludge (26) and in irrigation systems (7), where they are associated with bulking and clogging of drip holes, respectively. In marine environments, Thiothrix-like bacteria are found in microbial mats at hydrothermal vents (27) and as gut symbionts of invertebrates (25).

Historically, observations of filamentous sulfur bacteria belonging to the genera Thiothrix and Beggiatoa were an important stage in Winogradsky's work which eventually led to the concept of bacterial chemosynthesis (29). However, it was only recently that workers confirmed Winogradsky's assumption that Thiothrix strains may be capable of autotrophic growth. It was found that Thiothrix ramosa, an isolate obtained from a spring in Latvia, grows by using either thiosulfate or carbon disulfide as a sole energy source (16). Since the claim of Keil that he had grown a Thiothrix strain autotrophically was later repudiated (21), Thiothrix ramosa is the first representative of this genus that was cultivated in an inorganic medium. All other officially recognized Thiothrix isolates grow only heterotrophically or chemolithoheterotrophically (12).

The members of the genus Thiothrix apparently have versatile metabolic capabilities, and the defining characteristics of this genus are based largely on morphology $(12,13)$. Recently, monoclonal antibodies that recognize a variety of Thiothrix strains have been developed, suggesting that these bacteria may be related (4). However, the reliability of such criteria for phylogenetic definition of the genus is not clear. Furthermore, we wanted to see whether the species that are able to grow autotrophically are related to species which have never been grown autotrophically. In this study we investigated the relationship of Thiothrix ramosa to Thiothrix nivea and other mem-

\footnotetext{
* Corresponding author.

$\dagger$ Contribution no. 8993 of the Woods Hole Oceanographic Institution.

$\ddagger$ Present address: Institute of Microbiology, Russian Academy of Sciences, Moscow, Russia.
}

bers of the Proteobacteria by performing a 16S rRNA phylogenetic analysis. Thiothrix nivea has been shown to grow chemolithoheterotrophically and has been placed in the gamma subdivision of the Proteobacteria in previous analyses $(11,20)$.

\section{MATERIALS AND METHODS}

Culture methods and media. Thiothrix ramosa was obtained from the Institute of Microbiology, Russian Academy of Sciences, Moscow, Russia. The growth medium used contained (per liter) $0.5 \mathrm{~g}$ of $\left(\mathrm{NH}_{4}\right)_{2} \mathrm{SO}_{4}, 0.1 \mathrm{~g}$ of $\mathrm{MgSO}_{4} \cdot 7 \mathrm{H}_{2} \mathrm{O}$, $0.05 \mathrm{~g}$ of $\mathrm{CaCl}_{2} \cdot 2 \mathrm{H}_{2} \mathrm{O}, 0.11 \mathrm{~g}$ of $\mathrm{K}_{2} \mathrm{HPO}_{4}, 0.085 \mathrm{~g}$ of $\mathrm{KH}_{2} \mathrm{PO}_{4}, 1.0 \mathrm{ml}$ of a vitamin $\mathrm{B}$ mixture, and $1.0 \mathrm{ml}$ of a trace metal solution. The vitamin solution (2) and the trace metal solution ( 3 ) were filter sterilized separately and were added to the salt solution, which had been autoclaved. Sodium thiosulfate and sodium bicarbonate solutions were added to final concentrations of 4 and $5 \mathrm{mM}$, respectively.

The cells were grown in a chemostat by using a $300-\mathrm{ml}$ jacketed vessel connected to a thermocirculator (Haake, Paramus, N.J.), which was used to maintain the temperature at $23^{\circ} \mathrm{C}$. The culture was stirred continuously and bubbled with sterile air at a flow rate of $110 \mathrm{ml} \mathrm{min}{ }^{-1}$. The $\mathrm{pH}$ was maintained at a neutral value by automatic titration with a $1 \mathrm{M} \mathrm{Na}_{2} \mathrm{CO}_{3}$ stock solution by using a Fisher Accumet $\mathrm{pH}$ meter controller. The chemostat was inoculated $(10 \%, \mathrm{vol} / \mathrm{vol})$ with a thiosulfate-grown batch culture. Cells were harvested from a steady-state culture by centrifugation, frozen, and stored at $-80^{\circ} \mathrm{C}$.

Nucleic acid manipulation. Nucleic acids were extracted and purified by the method of Jarrel et al. (9), with slight modifications. Briefly, cells previously stored at $-80^{\circ} \mathrm{C}$ were ground in liquid nitrogen. TE buffer $(5 \mathrm{ml})$ was added to the frozen cell slurry, and the mixture was allowed to thaw on ice. Then sodium dodecyl sulfate and proteinase $\mathrm{K}$ were added to final concentrations of $1 \%$ and $50 \mu \mathrm{g} / \mathrm{ml}$, respectively. After the mixture had been incubated at $60^{\circ} \mathrm{C}$ for $1 \mathrm{~h}$, $\mathrm{NaCl}$ was added to a concentration of $0.5 \mathrm{M}$, and the preparation was incubated on ice for an additional $1 \mathrm{~h}$. The lysate was cleared by centrifugation at $25,000 \times$ $g$ for $15 \mathrm{~min}$. The supernatant was transferred, and the nucleic acids were precipitated with an equal volume of cold isopropanol. The precipitate was collected and dissolved in TE buffer to which RNase A was added. The final extraction was performed by using standard phenol-chloroform and chloroform treatment methods followed by ethanol precipitation.

A PCR was used to generate $16 \mathrm{~S}$ ribosomal DNA for direct sequencing. The PCR mixture contained approximately $100 \mathrm{ng}$ of template DNA, universal Bacteria primers $27 \mathrm{f}$ and $1492 \mathrm{r}(10)$ (100 pmol each), and $2.5 \mathrm{mM} \mathrm{MgCl}_{2}$. Depending on the intended direction of sequencing, one of the two amplification primers was biotinylated. The DNA was denatured at $94^{\circ} \mathrm{C}$ for $2 \mathrm{~min}$, and this was followed by 35 cycles consisting of $1 \mathrm{~min}$ at $94^{\circ} \mathrm{C}, 60 \mathrm{~s}$ at $50^{\circ} \mathrm{C}$, and $2 \mathrm{~min}$ at $72^{\circ} \mathrm{C}$.

The PCR product was sequenced directly by the method of Hultman et al. (8), in which avidin-coated magnetic beads are used. The biotinylated PCR product was bound to these beads and then denatured and washed while it was on the beads. The standard Sequenase (U.S. Biochemicals) protocol was used for sequencing reactions. The sequencing primers used were primers 1492r, 1392r, $1101 \mathrm{r}, 907 \mathrm{r}, 690 \mathrm{r}, 519 \mathrm{r}$, and $342 \mathrm{r}$ for the rRNA-like strand and primers $1115 \mathrm{f}$. $704 \mathrm{f}, 357 \mathrm{f}$, and $27 \mathrm{f}$ for the opposite strand (10).

Phylogenetic analysis. The Thiothrix ramosa $16 \mathrm{~S}$ rRNA secondary structure was reconstructed manually by using templates published by the Ribosomal Database Project (14) to help identify homologous sequence positions. Sequences were aligned manually in the Genetic Data Environment (19). All of the reference sequences and the basic alignment to which the Thiothrix ramosa 
TABLE 1. Evolutionary distance matrix for Thiothrix ramosa and representative members of the Proteobacteria ${ }^{a}$

\begin{tabular}{|c|c|c|c|c|c|c|c|c|c|c|c|c|c|c|c|c|c|}
\hline \multirow[b]{2}{*}{ Organism } & \multicolumn{17}{|c|}{ \% Evolutionary distance to: } \\
\hline & 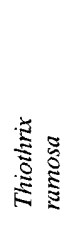 & 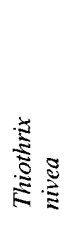 & 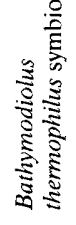 & 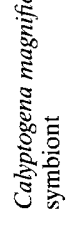 & 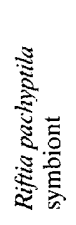 & 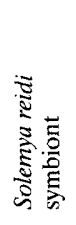 & 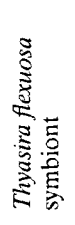 & 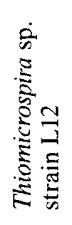 & 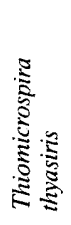 & 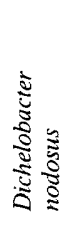 & 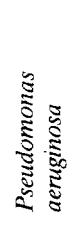 & 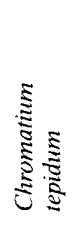 & 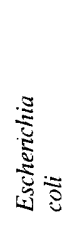 & 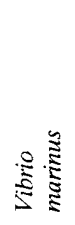 & $\begin{array}{l}\frac{3}{14} \\
0 \\
0 \\
0\end{array}$ & 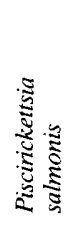 & 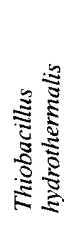 \\
\hline Thiothrix nivea & 93.6 & & & & & & & & & & & & & & & & \\
\hline Bathymodiolus thermophilus symbiont ${ }^{b}$ & 83.6 & 84.1 & & & & & & & & & & & & & & & \\
\hline Calyptogena magnifica symbiont ${ }^{b}$ & 83.8 & 84.0 & 92.6 & & & & & & & & & & & & & & \\
\hline Riftia pachyptila symbiont ${ }^{b}$ & 86.4 & 86.0 & 88.2 & 85.5 & & & & & & & & & & & & & \\
\hline Solemya reidi symbiont $t^{b}$ & 83.3 & 84.3 & 83.6 & 82.5 & 89.9 & & & & & & & & & & & & \\
\hline Thyasira flexuosa symbiont ${ }^{\prime \prime}$ & 85.2 & 86.1 & 85.6 & 84.9 & 94.1 & 88.2 & & & & & & & & & & & \\
\hline Thiomicrospira sp. strain L12 & 80.1 & 79.3 & 81.6 & 80.9 & 85.3 & 83.7 & 84.4 & & & & & & & & & & \\
\hline Thiomicrospira thyasinis & 80.1 & 79.9 & 83.0 & 82.3 & 84.3 & 83.6 & 84.2 & 90.6 & & & & & & & & & \\
\hline Pseudomonas aeruginosa & 82.4 & 83.4 & 83.1 & 83.3 & 87.7 & 87.6 & 86.1 & 81.7 & 83.9 & 83.2 & & & & & & & \\
\hline Chromatium tepidum & 83.5 & 83.3 & 78.4 & 78.9 & 86.1 & 85.2 & 84.0 & 79.0 & 79.6 & 81.8 & 83.5 & & & & & & \\
\hline Escherichia coli & 79.4 & 79.6 & 80.4 & 78.9 & 81.8 & 82.0 & 83.0 & 78.5 & 79.1 & 80.7 & 84.2 & 80.7 & & & & & \\
\hline Vibrio marinus & 80.2 & 80.9 & 81.2 & 80.7 & 82.5 & 83.2 & 82.7 & 80.5 & 82.2 & 80.0 & 84.7 & 80.3 & 86.6 & & & & \\
\hline Clone FL5 & 82.9 & 82.7 & 84.5 & 82.1 & 85.1 & 85.2 & 86.2 & 81.9 & 82.9 & 82.9 & 84.1 & 79.0 & 82.5 & 80.8 & & & \\
\hline Piscirickettsia salmonis & 83.0 & 84.3 & 80.9 & 82.4 & 84.2 & 85.2 & 84.4 & 83.1 & 81.8 & 83.5 & 84.8 & 82.1 & 83.2 & 82.7 & 82.8 & & \\
\hline Thiobacillus hydrothermalis & 82.4 & 82.5 & 82.3 & 82.1 & 84.9 & 86.6 & 85.1 & 78.6 & 81.4 & 83.8 & 84.8 & 83.8 & 82.6 & 79.3 & 82.1 & 83.9 & \\
\hline Neisseria gonorrhoeae & 78.8 & 79.9 & 76.7 & 75.9 & 81.4 & 80.1 & 80.3 & 75.7 & 75.9 & 81.3 & 81.3 & 78.6 & 79.2 & 76.0 & 80.3 & 78.5 & 81.8 \\
\hline
\end{tabular}

a Evolutionary distance values were calculated from the alignment used in the phylogenetic analyses by using the correction of Jukes and Cantor.

' A sulfur-oxidizing, chemoautotrophic symbiont.

sequence was added were obtained from the Ribosomal Database Project. Se quences were chosen from previously published work and on the basis of high levels of similarity to the Thiothrix ramosa sequence by using the BLAST program (1). Initially, a larger set of sequences was used, and outgroups were removed one at a time; remaining nucleotide positions were kept if the topology of the tree did not change. The final data set included 845 nucleotide positions.

Phylogenetic analyses were performed by using the distance, parsimony, and maximum-likelihood methods. Distance and bootstrap analyses were performed by using the program DNADIST with the Jukes-Cantor correction, the program SEQBOOT with 100 replicates, and the program FITCH with input randomization and global rearrangement. All of these programs are contained in the PHYLIP 3.4 package (6) and were implemented through the Genetic Data Environment (19). The parsimony analysis, including the bootstrap analysis, was performed by using PAUP 3.0 (22). For the maximum-likelihood analysis we used the fastDNAml program available from the Ribosomal Database Project Trees were constructed by allowing jumbled addition of taxa and global rearrangement of the branches. Bootstrap values are shown if they were greater than $50 \%$.

Nucleotide sequence accession numbers and strain designations. The $16 \mathrm{~S}$ ribosomal DNA sequence of Thiothrix ramosa has been deposited in the GenBank database under accession number U32940. The other organisms, and/or GenBank accession numbers of the other sequences used in our analysis are as follows: Bathymodiolus thermophilus symbiont, M99445; Calyptogena magnifica symbiont, M99446; clone FL5, L10936; Chromatium tepidum MC $^{\mathrm{T}}$ (= ATCC $\left.43061^{\mathrm{T}}\right)(\mathrm{T}=$ type strain $)$, M59150; Dichelobacter nodosus 198A $(=$ ATCC 27521) (reference strain), M35016; Escherichia coli, J01695; Neisseria gonor-

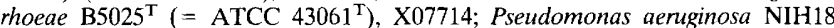
$\left(=\right.$ ATCC 25330), X60783; Pseudorickettsia salmonis $\mathrm{LF}^{-89^{\mathrm{T}}}(=\mathrm{ATCC}$ VR $1361^{\mathrm{T}}$ ), X60783; Riftia pachyptila symbiont, M99451; Solemya reidi symbiont, L07864; Thiomicrospira sp. strain L12, L01576; Thiobacillus hydrothermalis $\mathrm{r3}^{\mathrm{T}}$ (= DSM 7121 ${ }^{\mathrm{T}}$ ), M90662; Thyasira flexuosa symbiont, L01575; Thiothrix nivea $\mathrm{JP}^{\mathrm{T}}$ (= ATCC $35100^{\mathrm{T}}$ [neotype strain]), M79435, M79436, and M79437; Thiomicrospira thyasiris TG2 ${ }^{\mathrm{T}}$ (= DSM $5322^{\mathrm{T}}$ ), L01479; and Vibrio marinus MP1 $(=$ ATCC 15381) (source, C. R. Woese).

\section{RESULTS AND DISCUSSION}

A single product was obtained from PCR amplification of Thiothrix ramosa DNA. Direct sequencing of this product yielded 1,430 nucleotides of uninterrupted sequence in the region between nucleotide position 12 and nucleotide position 1441 (E. coli numbering). The secondary structure of the Thio- thrix ramosa sequence was very similar to the secondary structure of the Thiothrix nivea sequence, as determined by manual reconstruction. One noteworthy characteristic was the absence of the stem corresponding to positions 455 to 477 , which is also missing in Thiothrix nivea (11). This is unusual in members of the gamma subdivision of the Proteobacteria and appears to be a unique feature of the genus Thiothrix. A similarity matrix constructed with the Jukes-Cantor correction and aligned sequences obtained from the Ribosomal Database Project showed that the level of similarity between the two Thiothrix sequences was $93.6 \%$, while the levels of similarity to the sequences of other members of the gamma subdivision of the Proteobacteria were approximately $10 \%$ lower (Table 1).

Our phylogenetic analysis revealed that the two Thiothrix species clearly form a distinct group belonging to the gamma subdivision of the Proteobacteria (Fig. 1). These organisms fell into a single clade with all three analysis methods used; the bootstrap values were $100 \%$ in both the distance and parsimony analyses, and the branch was significantly positive at $P<$ $0.01 \%$ in the maximum-likelihood analysis. The overall position of the genus Thiothrix was near the group containing endosymbiotic, chemoautotrophic symbionts, as reported previously $(11,17)$. However, this node did not bootstrap significantly and changed position slightly with the different methods which we used, while the overall topology of the tree was unchanged. While the genus Thiothrix does belong to the gamma subdivision of the Proteobacteria, its closest relatives in this systematic unit cannot be determined with certainty yet.

Thiothrix strains have often been distinguished solely on the basis of morphology. However, experience has shown that morphological criteria are generally unreliable as tools in bacterial phylogenetic systematics (28). Our results indicate that the genus Thiothrix may be one of the few genera that can be identified by appearance. Among the filamentous sulfur bacteria, holdfast formation and growth in rosettes are unique to 


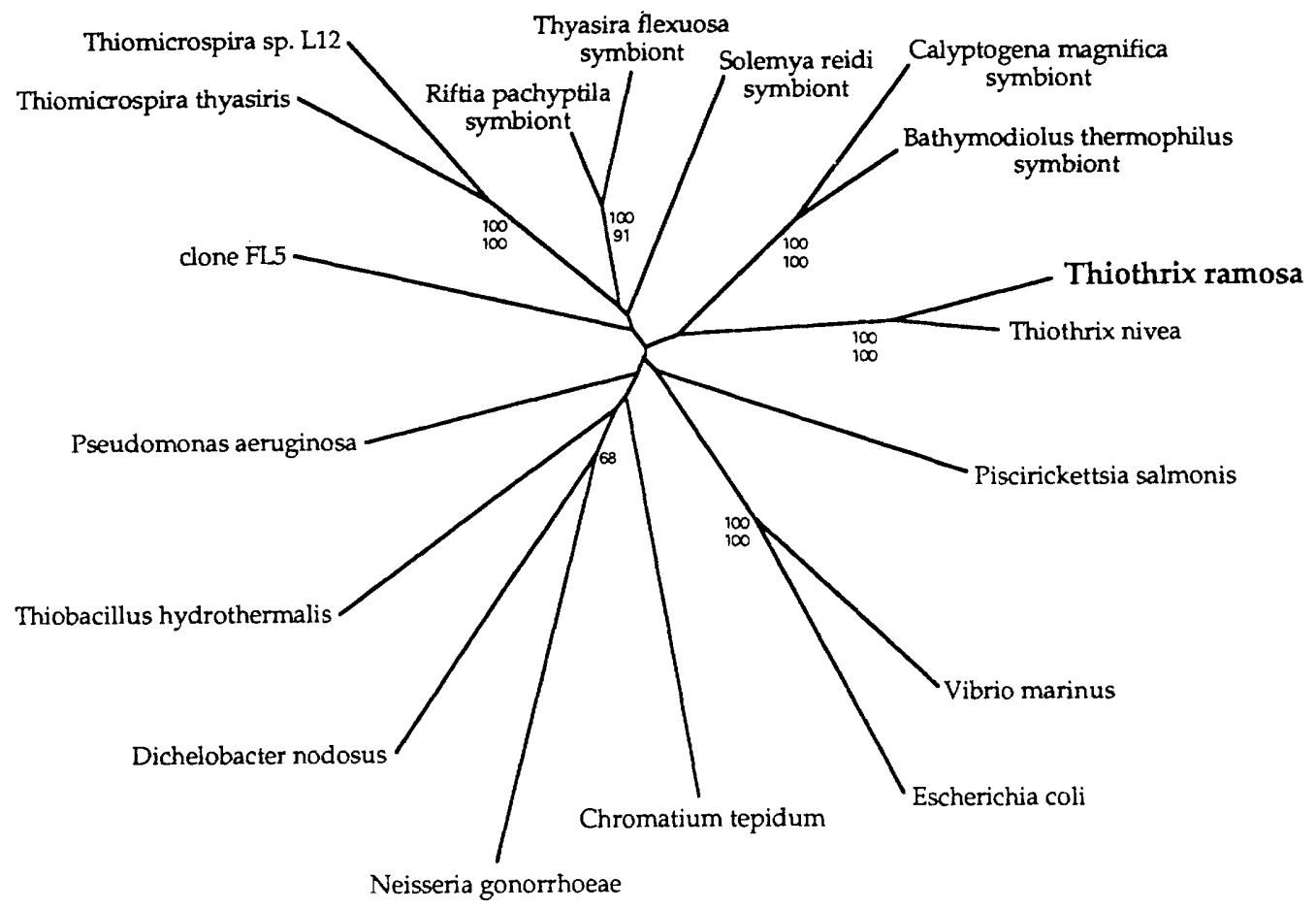

FIG. 1. Unrooted evolutionary distance tree based on the 16S rRNA sequences of Thiothrix ramosa and representative members of the Proteobacteria. All of the bacteria shown on the tree except $N$. gonorrhoeae belong to the gamma subdivision of the Proteobacteria; $N$. gonorrhoeae is a member of the beta subdivision of the Proteobacteria. Bootstrap values greater than $50 \%$ are shown at the nodes; the upper values are values obtained in the distance analysis, and the lower values are values obtained in the parsimony analysis. Bar $=5 \%$ nucleotide difference per sequence position.

the genus Thiothrix (23). The only other organism that a Thiothrix strain may currently be mistaken for is Leucothrix mucor. On the one hand, these bacteria are also filamentous, grow in rosettes, and form gonidia; on the other hand, they are purely heterotrophic, never accumulate sulfur globules, and do not have a sheath (5). So far, Leucothrix strains have been isolated only from marine environments, and pure cultures of Thiothrix strains have been obtained only from freshwater sources. However, some Thiothrix-like organisms observed at marine hydrothermal vents do not have a sheath and vary in cell length and width (15a). At this time the genus Thiothrix is distinguished from the genus Leucothrix on the basis of the presence of a sheath and sulfur accumulation, but it is not clear whether these are distinguishing features that reflect the natural relationship of these organisms. This issue can only be resolved by a phylogenetic analysis of Leucothrix strains and filamentous bacteria isolated from natural samples.

Autotrophy may be one of the defining characteristics of the genus Thiothrix. Since the isolation of Thiothrix ramosa, at least two additional strains that are able to grow autotrophically on reduced sulfur compounds have been described $(23,24)$. Like the study of Beggiatoa strains, which took over 100 years to be grown autotrophically (15), the study of Thiothrix strains was hampered for a long time by difficulties in obtaining pure cultures. Thiothrix nivea was the first species to be isolated and characterized in detail (12). This organism appears to require a source of reduced sulfur for growth, and it has been suggested that Thiothrix nivea is an obligate chemolithoheterotroph (13). Attempts to grow Thiothrix nivea autotrophically and to measure the activity of the $\mathrm{CO}_{2}$-fixing enzyme of the Calvin-Benson cycle, ribulose-1,5-bisphosphate carboxylaseoxygenase, have failed so far. However, this species may possess the genetic potential to grow autotrophically since genes encoding the large subunit of ribulose-1,5-bisphosphate carboxylase-oxygenase have been detected by DNA hybridization (18). Other Thiothrix strains have only been grown heterotrophically, and in many cases it is not clear whether these organisms have been tested for lithotrophy. Thus, a reexamination of these strains may be valuable for determining if growth in inorganic medium is one of the defining features of the genus Thiothrix.

Overall, our results should give confidence to workers who identify Thiothrix strains in environmental samples on the basis of morphological characteristics. Future tests may reveal how widely distributed autotrophy is in this genus.

\section{ACKNOWLEDGMENTS}

This work was supported by grants from the National Science Foundation and the Office of Naval Research to C.M.C.

\section{REFERENCES}

1. Altschul, S. F., W. Gish, W. Miller, E. W. Myers, and D. J. Lipman. 1990 Basic local alignment search tool. J. Mol. Biol. 215:403-410.

2. Bazylinski, D. A., C. O. Wirsen, and H. W. Jannasch. 1989. Microbial utilization of naturally occurring hydrocarbons at the Guyamas Basin hydrothermal vent site. Appl. Environ. Microbiol. 55:2832-2836.

3. Biebl, H., and N. Pfennig. 1978. Growth yields of green sulfur bacteria in 
mixed culture with sulfur and sulfate reducing bacteria. Arch. Microbiol. 117:9-16.

4. Brigmon, R. L., G. Bitton, S. G. Zam, and B. O'Brien. 1995. Development and application of monoclonal antibody against Thiothrix spp. Appl. Environ. Microbiol. 61:13-20.

5. Brock, T. D. 1992. The genus Leucothrix, p. 3247-3255. In A. Balows, H. G. Trüper, M. Dworkin, W. Harder, and K.-H. Schleifer (ed.), The prokaryotes, 2nd ed. Springer-Verlag, New York.

6. Felsenstein, J. 1989. Phylip--phylogeny inference package. Cladistics 5:164166.

7. Ford, H. W., and D. P. H. Tucker. 1975. Blockage of drip irrigation filters and emitters by iron-sulfur-bacterial products. Hortic. Sci. (Stuttgart) 10:62-64.

8. Hultman, T., S. Stahl, E. Hornes, and M. Uhlen. 1989. Direct solid phase sequencing of genomic and plasmid DNA using magnetic beads as solid support. Nucleic Acids Res. 17:4937-4946.

9. Jarrell, K. F., D. Faguy, A. M. Herbert, and M. L. Kalmkoff. 1991. A general method of isolating high molecular weight DNA from methanogenic archaea (archaebacteria). Can. J. Microbiol. 38:65-68.

10. Lane, D. J. 1991. 16S/23S rRNA sequencing, p. 115-175. In E. Stackebrandt and M. Goodfellow (ed.), Nucleic acid techniques in bacterial systematics. Wiley \& Sons, Chichester, United Kingdom.

11. Lane, D. J., A. P. Harrison, D. Stahl, B. Pace, S. J. Giovannoni, G. J. Olsen, and N. R. Pace. 1992. Evolutionary relationship among sulfur- and ironoxidizing eubacteria. J. Bacteriol. 174:269-278.

12. Larkin, J. M. 1989. Genus II. Thiothrix Winogradsky 1888, p. 2098-2101. In J. T. Staley, M. P. Bryant, N. Pfennig, and J. G. Holt (ed.), Bergey's manual of systematic bacteriology, vol. 3. Williams and Wilkins, Baltimore.

13. Larkin, J. M., and W. R. Strohl. 1983. Beggiatoa, Thiothrix, and Thioploca. Annu. Rev. Microbiol. 37:341-367.

14. Larsen, N., G. J. Olsen, B. L. Maidak, M. J. McCaughey, R. Overbeck, T. J. Macke, T. L. Marsh, and C. R. Woese. 1993. The Ribosomal Database Project. Nucleic Acids Res. 21:3021-3023.

15. Nelson, D. C., and H. W. Jannasch. 1983. Chemoautotrophic growth of a marine Beggiatoa in sulfide-gradient cultures. Arch. Microbiol. 136:262-269.

15a.Odintsova, E. V., and H. W. Jannasch. Unpublished data.

16. Odintsova, E. V., A. P. Wood, and D. P. Kelly. 1993. Chemolithoautotrophic growth of Thiothrix ramosa. Arch. Microbiol. 160:152-157.

17. Polz, M. F., D. L. Distel, B. Zarda, R. Amann, H. Felbeck, J. A. Ott, and C. M. Cavanaugh. 1994. A highly specific association between ectosymbiotic, sulfur-oxidizing bacteria and a marine nematode and its phylogenetic relationship to endosymbionts and free-living bacteria. Appl. Environ. Microbiol. 60:4461-4467.

18. Shively, J. M., W. Devore, L. Stratford, L. Porter, L. Medlin, and S. E. J. Stevens. 1986. Molecular evolution of the large subunit of ribulose-1,5bisphosphate carboxylase/oxygenase (RuBisCO). FEMS Microbiol. Lett. 37: 251-257.

19. Smith, S. W., R. Overbeck, W. Gilbert, and P. M. Gillevet. 1994. The Genetic Data Environment: an expandable GUI for multiple sequence analysis. CABIOS 10:671-675.

20. Stahl, D. A., D. J. Lane, G. J. Olsen, D. J. Heller, T. M. Schmidt, and N. R. Pace. 1987. Phylogenetic analysis of certain sulfide-oxidizing and related morphologically conspicuous bacteria by $5 \mathrm{~S}$ rRNA ribosomal ribonucleic acid sequences. Int. J. Syst. Bacteriol. 37:116-122.

21. Strohl, W. R., and T. M. Schmidt. 1984. Mixotrophy of colorless, sulfideoxidizing gliding bacteria Beggiatoa and Thiothrix, p. 79-95. In W. R. Strohl and O. H. Tuovinen (ed.), Microbial chemoautotrophy. Ohio State University Press, Columbus.

22. Swofford, D. L. 1991. PAUP: phylogenetic analysis using parsimony. Illinois Natural History Survey, Champaign.

23. Tandoi, V., N. Caravaglio, L. Cavalca, D. Schweiger, and A. Zoppini. 1994. Isolation of a chemolithotrophic, mixotrophic, and heterotrophic Thiothrix strain. Ann. Microbiol. Enzimol. 44:141-151.

24. Tandoi, V., N. Caravaglio, D. Di Dio Balsamo, M. Majone, and M. C. Tomei. 1994. Isolation and physiological characterization of Thiothrix sp. Water Sci. Technol. 29:261-269.

25. Temara, A., C. de Ridder, J. G. Kuenen, and L. A. Robertson. 1993. Sulfideoxidizing bacteria in the burrowing echinoid, Echinocardium cordarum (Echinodermata). Mar. Biol. 115:179-185.

26. Williams, T. M., and R. F. Unz. 1985. Isolation and characterization of filamentous bacteria present in bulking activated sludge. Appl. Microbiol. Biotechnol. 22:273-282.

27. Wirsen, C. O., H. W. Jannasch, and S. J. Molyneaux. 1993. Chemosynthetic microbial activity at Mid-Atlantic Ridge hydrothermal vent sites. J. Geophys. Res. 98:9693-9703.

28. Woese, C. R. 1987. Bacterial evolution. Microbiol. Rev. 51:221-271.

29. Zavarzin, G. A. 1989. Sergei N. Winogradsky and the discovery of chemosynthesis, p. 17-32. In H. G. Schlegel and B. Bowien (ed.), Autotrophic bacteria. Springer, Berlin. 